
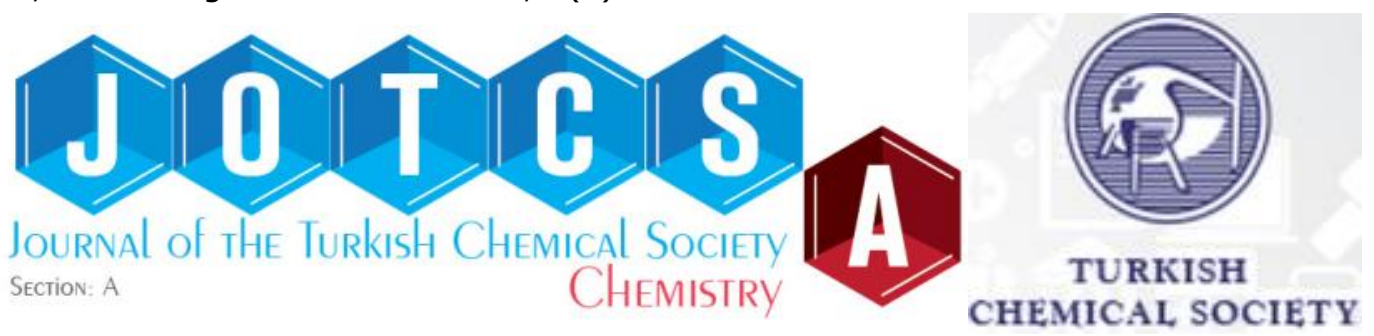

\title{
Salvadora persica Extract-laden Jellyfish Collagen Hybrid Constructs for Periodontal Tissue Regeneration
}

\author{
Yavuz Emre Arslan $*$ and Ilkim Kantarcioglu \\ Regenerative Biomaterials Laboratory, Department of Bioengineering, Engineering Faculty, \\ Canakkale Onsekiz Mart University, Canakkale 17100, Turkey
}

Abstract: Considerable effort in the field of periodontal tissue engineering has been expended in the construction of advanced biomatrix for the treatment of periodontal diseases caused by poor oral hygiene, malnutrition, genetic factors, and systemic disorders. With these in mind, the ultimate goal of this investigation is to fabricate sophisticated scaffolds using jellyfish collagen (JC) and aqueous Salvadora persica (Miswak) extracts. Rhizostoma pulmo species JC was isolated and characterized in depth. Miswak was extracted using two different methods. The extraction yield was calculated to be $14.2 \pm 0.9 \%$ and $17.1 \pm 0.4 \%$ for Methods I and II, respectively. Gas chromatography-mass spectroscopy (GC-MS) results revealed the extract to be composed of 1,8 -cineole $(49.3 \%)$, benzyl nitrile $(36.2 \%)$, benzyl isothiocyanate $(5.9 \%)$, limonene $(2.4 \%)$, eugenol $(0.8 \%)$, and palmitic acid $(0.3 \%)$. Total phenolic content and antioxidant capacities of the extracts were also determined by spectrophotometric means. Human periodontal ligament fibroblast cells were isolated and expanded. Cell viability on JC and miswak extract-laden JC scaffolds was determined by 3-(4,5-dimethylthiazol2-yl)-2,5-diphenyltetrazolium Bromide (MTT) assay. Microarchitectures of the JC, 0.05 and $0.1 \%$ miswak extract-laden JC scaffolds and also cellular behaviors on these surfaces were evaluated by scanning electron microscopy (SEM) analysis. This study suggests that miswak extract-laden JC scaffolds would present new opportunities for periodontal tissue engineering.

Keywords: Salvadora persica, Miswak, Jellyfish collagen, Human periodontal ligament fibroblasts, Periodontal tissue engineering, Translational medicine

Submitted: November 19, 2018. Accepted: January 22, 2019.

Cite this: Arslan Y, Kantarcioglu I. Salvadora persica Extract-laden Jellyfish Collagen Hybrid Constructs for Periodontal Tissue Regeneration. JOTCSA. 2019;6(1):51-62.

DOI: https://dx.doi.org/10.18596/jotcsa.484936.

*Corresponding author: E-mail: yavuzea@gmail.com. Tel.: +90-286-218-0018; Fax: +90-286218-0541.

\section{INTRODUCTION}

Periodontal ligament fibroblast (PDLF) cells, embryologically-derived from the ectomesenchymal tissue of the dental follicle and embedded in the periodontal tissue, are a connective tissue element with spindle-shaped fibroblastic morphology $(1,2)$. The periodontal tissue is a complex structure, which consists of gingiva, periodontal ligament (PDL), cementum and the alveolar bone (3). When the microbial equilibrium shifts in favor of pathogens due to deteriorating oral hygiene, also referred to as the periodontitis, a common chronic inflammatory gingival disease, causes loss of tooth-supporting constituents (e.g.,
PDL, alveolar bone) $(3,4)$. In the pathogenesis of the periodontitis, there are gingival inflammation, gingival pocket formation, periodontal ligament destruction and finally alveolar bone resorption. With the progression of the disease, loss of tooth may also occur. Interestingly, recent studies have demonstrated that periodontitis is related to many systemic diseases such as diabetes mellitus, cardiovascular diseases, and rheumatoid arthritis $(5,6)$.

Current treatment approaches for maintenance or regeneration of damaged tooth-supporting constituents caused by periodontal diseases aim at fabricating novel 
bioengineered scaffolds by taking advantage of translational medicine \& tissue engineering concepts which employ the knowledge of cells, materials, soluble factors, and so on for their use in clinical arena $(7,8)$. Different synthetic or naturally-derived biopolymers and/or their composites with biominerals have evolved since last decades in periodontal tissue engineering applications (9-11).

Collagen is a structural extracellular matrix protein and can easily be extracted from many tissue types (e.g., skin, tendon). It has unique properties such as self-assembling into fibrillar structures under physiological conditions, high level biocompatible and biodegradability, mechanical and homeostatic qualities, which make it a significant candidate in regenerative medicine applications (12-14). However, there are limitations in the use of mammalianderived collagen in clinical purposes because they tend to carry some risks such as bovine spongiform encephalopathy and foot-andmouth disease. In addition, collagen from porcine skin or tendon is not preferred by the patients due to religious concerns $(15,16)$. Thus, marine-derived collagen is considered to be an alternative and probably a safer source in the construction of bioengineered scaffolds compared to mammals. In the current literature, jellyfish-derived collagen has been used as a hybrid construct for chondrogenesis of human mesenchymal stem cells (hMSCs) $(15,17)$, a composite scaffold for osteogenic differentiation of human adipose-derived MSCs (18) and an aptasensor substrate for detection of blood thrombin levels in different neurological diseases (19). Furthermore, it has been reported that jellyfish-derived collagen has the potential to activate bone marrow-derived dendritic cells, which also proves its immunoregulatory function (20).

Medicinal plants, which are almost as old as human history, have been used in various civilizations of the world for thousands of years to treat many health problems (21-23). Miswak, also recommended by the World Health Organization as an oral hygiene tool for mechanically removing plaque and food residues from the teeth, has great potential due to its substantial components such as minerals (e.g., sulfur, chlorides, fluorides, silica) and phytochemicals (e.g., tannins, benzyl isothiocyanate) which are related to dental care $(24,25)$. Although aqueous, alcoholic, or nonpolar extracts of miswak contain various antimicrobial agents, it was reported that the aqueous extract had shown better antimicrobial activity compared to other solvents (26).

In this work, 3-dimensional (3D) hybrid constructs were fabricated using marinederived collagen and miswak extracts for periodontal tissue engineering applications.
Aqueous extracts from miswak sticks were prepared using two different methods to evaluate the extraction yield. The bioactive constituents in the miswak extracts were then analyzed by GC-MS. Total phenolic contents and antioxidant activities were also determined spectrophotometrically. Jellyfish collagen was isolated and well-characterized using different analysis methods (e.g., SDSPAGE, GC-MS, Lowry assay, TGA and ATRFTIR). Human periodontal ligament fibroblast cells were isolated, expanded and seeded on jellyfish collagen and miswak extract-laden jellyfish collagen scaffolds. MTT assay was applied to determine the number of viable cells on prepared scaffolds. Finally, the scaffold and cell/scaffold constructs were observed by scanning electron microscopy to evaluate the micro-architecture and cellular behaviors on these surfaces.

\section{MATERIALS AND METHODS}

\section{Materials}

S. persica sticks (origin of Pakistan) were purchased from a local seller of medicinal herbs in vacuum bags in the wet form. Rhizostoma pulmo species jellyfishes were collected from the coast of Dardanelles (Abydus), Çanakkale, Turkey. All chemicals were provided from Merck (Millipore-Sigma, Germany) unless otherwise noted.

\section{Preparation of miswak extracts}

The extraction process was carried out according to the procedure described by Abhary and Al-Hazmi (26), with slight modifications. Briefly, the outer layer of miswak sticks was carefully removed, and the sticks were cut into small pieces, then dried in an incubator (Memmert UN55, Germany) at 40 ${ }^{\circ} \mathrm{C}$ for three days. The dried miswak pieces were milled (IKA M20, Germany) to obtain a fine powder. Two different methods were applied in order to obtain aqueous extracts of miswak. The dried miswak powder was suspended in Milli-Q water (Merck-Millipore, Germany) at a ratio of $5 \%(w / v)$, and the suspension was vigorously stirred at room temperature (RT) for three days (described as Method I). Similarly, the suspension (5\%, w/v in Milli-Q water) was infused in a rotaryevaporator (Buchi, Rotavapor R210, Switzerland) at $80{ }^{\circ} \mathrm{C}$ for $1 \mathrm{~h}$ (described as Method II). The solutions were then centrifuged at $6000 \mathrm{rpm}$ for 15 minutes, and the resulting supernatants were filtered through Whatman No. 43 filter paper (Macherey-Nagel, Germany) under reduced pressure. The solutions were then concentrated using Rotary-evaporator and the miswak extracts were frozen at $-26{ }^{\circ} \mathrm{C}$, then freeze-dried (LyoQuest, Telstar, Spain) for overnight to obtain water-soluble miswak extracts. The lyophilized extracts were kept at $-26{ }^{\circ} \mathrm{C}$ until the time of analysis. The 
extraction yields were calculated using the equation given below. Step-by-step procedure of miswak extraction can be seen in Figure 1.

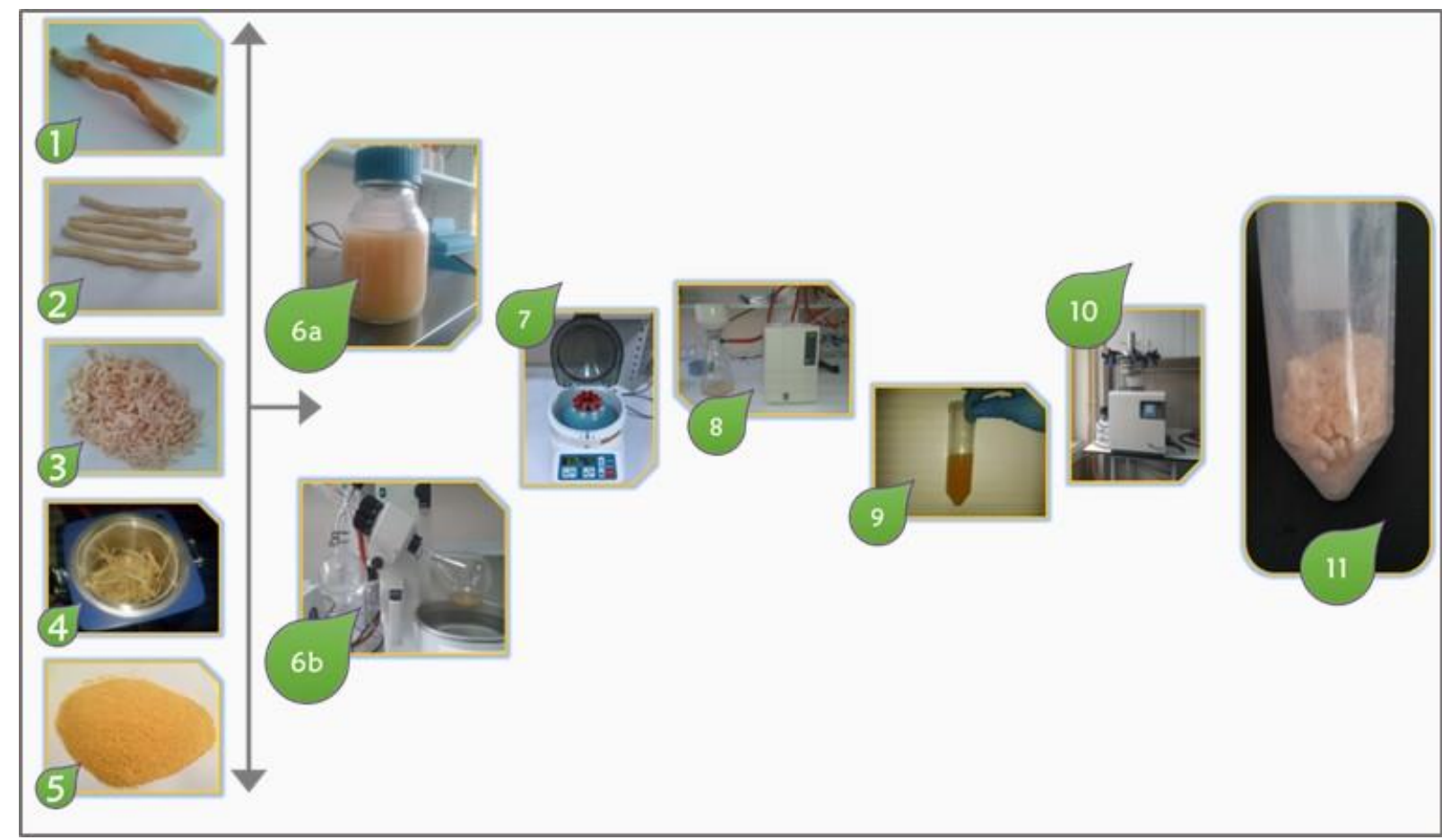

Figure 1. Step-by-step representation of the extraction process of Salvadora persica (Miswak). Raw miswak sticks (1), removing of outer layer (2), cutting (3), milling (4), obtaining fine powders (5), Method I (6a), Method II (6b), centrifugation (7), filtration (8), concentrated sticky miswak solution (9), lyophilization (10) and obtaining dry form of miswak extracts (11).

Yield $(\%)=[($ initial weight $($ dry $)-$ lyophilized weight $) /$ initial weight $($ dry $)] \times 100$ (1).

\section{Gas Chromatography-Mass spectroscopy analysis of extracts}

In order to identify the chemical composition of miswak extracts, the GC-MS analysis was conducted according to our previous study (21). Initially, lyophilized miswak extracts were dissolved in Milli-Q water and filtered through a $0.22 \mu \mathrm{m}$ sterile filter. Then, the extracts were loaded an instrument (Thermo MS Finnigan Trace DSQ, USA), with a DB-WAX column (30 $\mathrm{m} \times 0.25 \mathrm{~mm}$ i.d.; film thickness $0.25 \mu \mathrm{m})$. The oven temperature was adjusted as described as follows: $50^{\circ} \mathrm{C}$ for 1 minute, followed by an increase rate of $3{ }^{\circ} \mathrm{C} /$ minute up to $220^{\circ} \mathrm{C}$. Helium as a carrier gas was set to flow at a rate of $1 \mathrm{~mL} /$ minute. All data were evaluated using the Xcalibur software.

\section{Total phenolic content analysis of extracts}

The total phenolics of each extract were colorimetrically assessed according to the Folin-Ciocalteu method reported in the literature by Singleton and Rossi (27). In short, each extract $(10 \mathrm{mg}$ ) was dissolved in 1 $\mathrm{mL}$ of Milli-Q water at RT. Then, $900 \mu \mathrm{L}$ of Milli$\mathrm{Q}$ water, $5 \mathrm{~mL}$ of Folin reagent $(0.2 \mathrm{~N})$ and 4 $\mathrm{mL}$ of sodium carbonate solution $(7.5 \%, \mathrm{w} / \mathrm{v})$ were added into each $100 \mu \mathrm{L}$ of sample. The samples were left to stand in the dark at RT for 2 hours for color development and the absorbance at $765 \mathrm{~nm}$ was measured against blank solution (Shimadzu UV-mini 1240, Japan). The results were presented as $\mathrm{mg}$ of gallic acid equivalent (GAE) per $g$ of dry weight.

\section{CUPRAC assay for antioxidant capacity of extracts}

The antioxidant capacity levels of each extract were ascertained using the method described by Apak et al. (28). Following their work, 20 $\mu \mathrm{L}$ of each sample was mixed with $1 \mathrm{~mL}$ of $\mathrm{CuCl}_{2} .2 \mathrm{H}_{2} \mathrm{O}(0.01 \mathrm{M}$, prepared in Milli-Q water), $1 \mathrm{~mL}$ of neocuproine $\left(7.5 \times 10^{-3} \mathrm{M}\right.$, prepared in ethanol), $1 \mathrm{~mL}$ of ammonium acetate solution ( $1 \mathrm{M}$ in Tris-buffer, $\mathrm{pH}=7.0$ ) and $1.08 \mathrm{~mL}$ of Milli-Q water, each solution was allowed to rest at RT for 30 minutes in the dark. The absorbance was measured at 450 $\mathrm{nm}$ against the blank solution and the antioxidant capacity of extracts was expressed in terms of $\mathrm{mg}$ Trolox per liter.

\section{Isolation and characterization of marine- derived collagen from $R$. pulmo}

Jellyfish collagen (JC) was isolated from $R$. pulmo and characterized well according to the studies previously published by our group $(18,19)$. Briefly, jellyfish was cut into mediumsized pieces after being caught and transferred to our laboratory. Jellyfish pieces were then 
immersed into $99.9 \%$ ethyl alcohol and treated with $0.1 \mathrm{M} \mathrm{NaOH}$ for 24 hours in order to dehydrate and remove any non-collagen substances, respectively. Before being digested with pepsin (600-1200 U/mg) for three days, jellyfish pieces were blended (IKA T18 Basic, Germany) in 0.5 M acetic acid (1gram sheet per $100 \mathrm{~mL}$ solution). Following, the viscous solution was centrifuged at 10000 $\mathrm{g}$ for 1 minute and dialyzed against $0.02 \mathrm{M}$ dibasic sodium phosphate $(\mathrm{pH} 8.8)$ for three days for the purpose of inactivating the enzyme. The pepsin-soluble JC was frozen at $86{ }^{\circ} \mathrm{C}$ and freeze-dried overnight. The lyophilized form of the $\mathrm{JC}$ was stored at $-86^{\circ} \mathrm{C}$ until use in the experiments. In order to characterize pepsin-soluble JC, various experiments were carried out such as modified Lowry assay (for determining the protein concentration and purity), SDS-poly acrylamide gel electrophoresis (SDS-PAGE) (for determining the protein size, distribution, etc.), thermogravimetric analysis (TGA) (for determining the thermal properties), ATRFTIR, contact angle measurement, amino acid composition analysis using GC-MS and also hydroxyproline content analysis (for both raw and pepsin-soluble $\mathrm{JC}$ ). The results related to the analyses have been pointed out in the papers mentioned above.

\section{Fabrication of hybrid constructs from JC and miswak extracts}

To produce hybrid constructs from JC and miswak extracts, JC was first dissolved in Milli$\mathrm{Q}$ water at a ratio of $3 \%(\mathrm{w} / \mathrm{v})$. Then, the solution was poured into a 48-well plate, frozen immediately at $-86^{\circ} \mathrm{C}$ and then freezedried overnight (18). In order to enhance the mechanical properties of prepared scaffolds, cross-linking process was conducted using $\mathrm{N}$ - hydroxysuccinimide (NHS) / N-(3dimethylaminopropyl)-N'-ethylcarbodiimide hydrochloride (EDC) prepared in 2-(Nmorpholino)ethanesulfonic acid (MES) buffer ( $\mathrm{pH}$ 5.5) according to the method described by Buttafoco et al. (29), with slight modifications. In short, MES buffer was mixed with $99 \%$ ethanol at a ratio of $1: 9(\mathrm{v} / \mathrm{v})$ and cross-linkers were dissolved in this solution. The scaffolds were then immersed in ethanol ( $\geq 99 \%$ ) for 10 minutes and cross-linked for 8 hours at room temperature with gentle agitation (IncuShaker Mini, Benchmark Scientific, USA). The scaffolds were then thoroughly rinsed with Milli-Q water to eliminate excess cross-linker and freeze-dried overnight. The dimensions of the cross-linked scaffolds were measured to be $\mathrm{h}=3 \mathrm{~mm}$ and $\varnothing=6 \mathrm{~mm}$. Following this, lyophilized miswak extract was separately dissolved in Milli-Q water at ratios of 0.05 and $0.1 \%(\mathrm{w} / \mathrm{v}), 200 \mu \mathrm{L}$ of each extract solution was loaded into cross-linked scaffolds. Finally, the miswak extract-laden JC hybrid constructs were frozen at $-86{ }^{\circ} \mathrm{C}$ and lyophilized overnight.

\section{Swelling test}

Liquid handling capacities of the JC and miswak extract-laden JC scaffolds were determined by inserting the scaffolds in $30 \mathrm{~mL}$ of phosphate-buffer saline (PBS) solution $(\mathrm{pH}$ $=7.4$ ) at $37^{\circ} \mathrm{C}$ for 10 minutes. Initially, all of the dry scaffolds were weighed $\left(\mathrm{W}_{0}\right)$ before being immersed in PBS. After 10 minutes, the scaffolds were removed, gently wiped for any adsorbed buffer and weighed again $\left(W_{s}\right)$. The swelling ratio of scaffolds was calculated using the equation given below. Three independent measurements were carried out for the test (30).

$$
\text { Swelling ratio }(\%)=\left[\left(W_{s}-W_{0}\right) / W_{0}\right] \times 100
$$

\section{Isolation and expansion of human periodontal ligament fibroblast cells}

Human periodontal ligament fibroblast (hPDLF) cells were isolated from root surfaces of healthy premolars as described previously by Inanc et al. (9), with slight modifications. The experimental design was reviewed and approved by Clinical Research Ethics Committee, Faculty of Medicine, Çanakkale Onsekiz Mart University (permission number: 2016-02-04). Informed written consent was also obtained from each donor. Immediately after extraction, teeth were washed repeatedly (5 - 8 times) using sterile PBS $(\mathrm{pH}=7.4$ ) containing $5 \%$ penicillin-streptomycin in order to eliminate debris and blood located on dental surfaces. The periodontal layers were then scraped off gently middle third of the teeth roots and minced using a sterile surgical blade. Minced tissues were enzymatically digested in $0.1 \%$ collagenase (Type I, 0.25 - 1.0 FALGPA units/mg solid) for 45 minutes in a $\mathrm{CO}_{2}$ incubator (Panasonic, Japan), and the cell suspension was centrifuged (Hettich, Germany) at $300 \mathrm{~g}$ for 5 minutes. The pellet was then re-suspended in a culture medium consisting of DMEM (Dulbecco's modified Eagle's medium) supplemented with $10 \%$ fetal bovine serum (FBS), $1 \%$ penicillinstreptomycin, $1 \%$ non-essential amino acid stock solution, and \%1 L-glutamine (all from Biological Industries, USA), transferred to 6well plates and propagated at $37^{\circ} \mathrm{C}, 5 \% \mathrm{CO}_{2}$ and $95 \%$ relative humidity conditions. The cells were passed when reaching 80-90\% confluency. The spindle-shape fibroblastic morphology of hPDLF cells was observed by an inverted-phase contrast microscope (PrimoVert, Zeiss, Germany). Cells in the passages between $2-5$ were used in the experiments. 
Cell seeding on JC and miswak extractladen JC scaffolds

JC and miswak extract-laden JC scaffolds were sterilized under UV ( $254 \mathrm{~nm}$ ) exposure for 2 hours in a laminar air flow cabinet (Bio II Advance, Telstar, Spain). hPDLF cells were then seeded at a density of $2.4 \times 10^{5}$ cells/scaffolds and growth in DMEM high glucose supplemented with $10 \%$ fetal bovine serum (FBS), 1\% penicillin-streptomycin, 1\% nonessential amino acid stock solution, and $1 \%$ L-glutamine by replenishing the growth medium every 2 - 3 days. The culture was maintained under standard culture conditions (at $37^{\circ} \mathrm{C}, 5 \% \mathrm{CO}_{2}$ and $95 \%$ relative humidity) for 3, 7 and 14 days. Cell proliferation was quantified using MTT assay kit (Cell Growth Determination Kit, MTT based, CGD1, Merck) by following manufacturer's instructions at a wavelength of $570 \mathrm{~nm}$ on days 3,7 and 14 .

\section{Scanning electron microscopy}

The surface morphology of fabricated JC and miswak extract-laden JC scaffolds and cellular behaviors on these surfaces were observed by field-emission scanning electron microscopy (FE-SEM JFM 7100F EDS, JEOL, Japan). After being fixed with $2.5 \%$ glutaraldehyde (prepared in PBS) for at least 24 hours, the specimens were rinsed repeatedly with PBS $(\mathrm{pH} 7.2-7.4)$ and immersed in an ethanol series $(50,70,80,90,95$, and $100 \%$ ) for dehydration. Samples dried at RT were then sputter-coated with Pd-Au for 90 seconds so as to improve the electron conductivity in order to achieve better SEM micrographs. Images were taken at $10 \mathrm{kV}$ and different magnification levels in a high vacuum.

\section{Statistical analysis}

One-way analysis of variance (ANOVA) by followed Tukey tests were performed using Origin ProsSRO (v8.0724, Origin Lab Corporation, MA, USA) software to evaluate the results. Only variables with a confidence level higher than $95 \%(p \leq 0.05)$ were considered to be statistically significant. The mean \pm standard deviation of variables was also calculated with Microsoft Office Professional Plus 2016 Excel. The results presented in this study are the average of at least three independent measurements.

\section{RESULTS AND DISCUSSION}

\section{The performance of the extraction processes}

The techniques and also solvents used in the extraction process could affect the quantity and composition of bioactive compounds of miswak extract. According to the results, the extraction yields were found to be $14.2 \pm 0.9$ $\%$ and $17.1 \pm 0.4 \%$ for the Method I and II, respectively. In other studies related to the miswak extraction, various solvents or their mixtures were studied to achieve maximum crude extract. To this end, Mohamed and Khan (31) have tested $80 \%$ methanol, $80 \%$ ethanol, $80 \%$ acetone and water to determine the effects of such solvents on extraction yield of dried miswak (origin of Saudi Arabia). They have reported that highest yield was obtained when using $80 \%$ methanol (1.02 $\pm 0.05 \%$, $\mathrm{w} / \mathrm{w})$ compared to water (0.56 $\pm 0.01 \%$, $w / w)$. Interestingly, another study found that the yield of methanolic extract of Salvadora persica L. (origin of South of Algeria) was $45 \%$ (32).

\section{Evaluating the GC-MS results}

The biologically active constituents of aqueous miswak extract (Method II) were assessed with GC-MS. Six major compounds representing $95.1 \%$ of the aqueous miswak extract were detected. The main compound was found to be 1,8 -cineole $(49.3 \%)$ in addition to benzyl nitrile (36.2\%), benzyl isothiocyanate $(5.9 \%)$, limonene $(2.4 \%)$, eugenol $(0.8 \%)$ and palmitic acid (0.3\%) (Figure 2A). These findings correspond with the results reported by Noumi et al. (33) and Naeini et al. (34). Among these compounds, benzyl nitrile and benzyl isothiocyanate have a significant role in the antibacterial repertoire of miswak extract (35). On the other hand, the differences in the yields (\%) and chemical composition might be related to geological conditions, the season of the plant collection and in particular climate (36). 


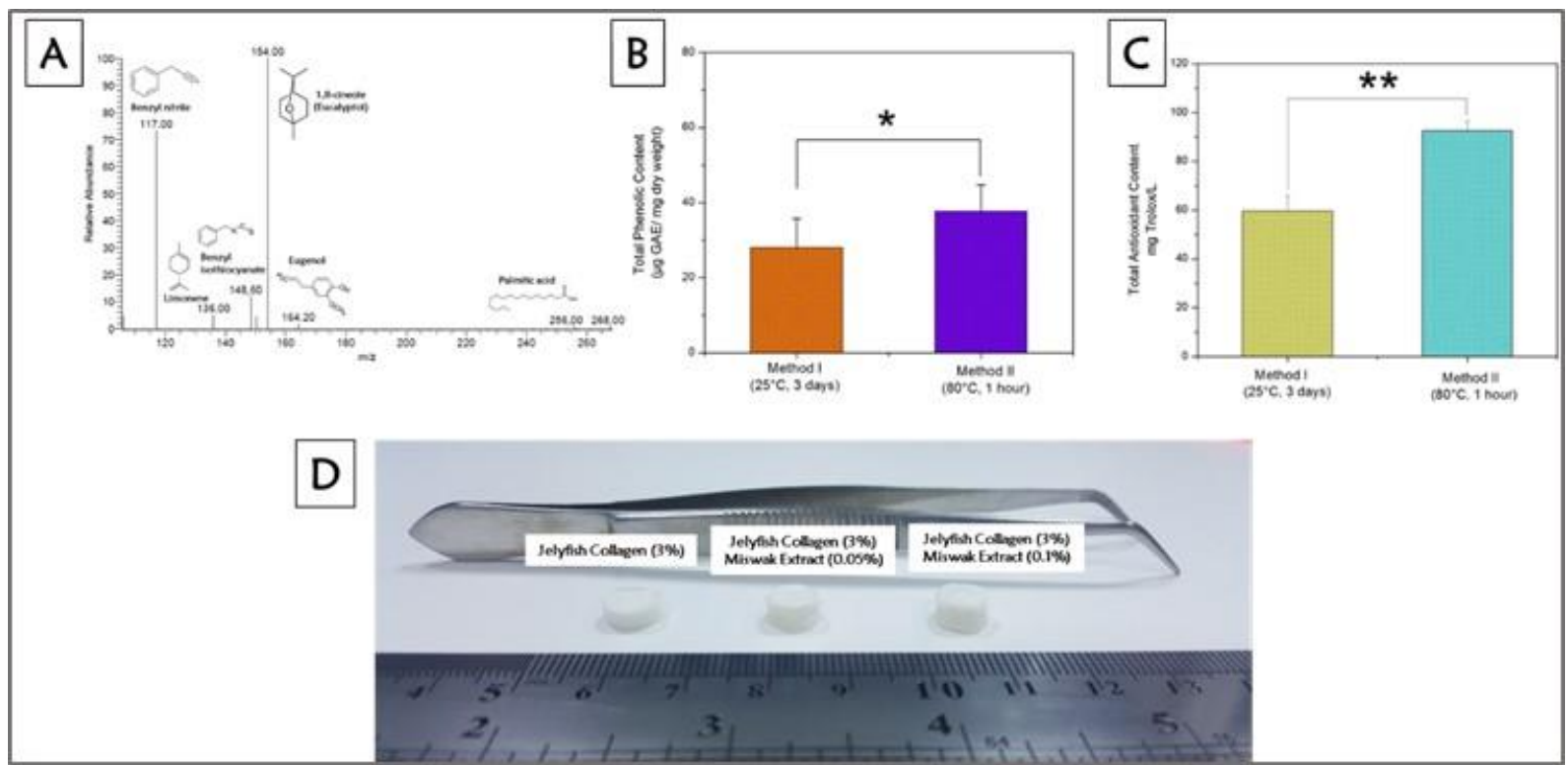

Figure 2. GC-MS analysis (A), total phenolic content (B), total antioxidant activity (C) and macroscopic images of the fabricated scaffolds (D).

\section{Total Extractable phenolics}

The total extractable phenolics of Salvadora persica were evaluated through total phenolic content (TPC) analysis. TPC of Salvadora persica was found to be $28.79 \pm 7.79$ and 37.7 $\pm 4.0 \mu \mathrm{g} \mathrm{GAE} / \mathrm{mg}$ dry weight for Method I and II, respectively. No significant difference ( $* \mathrm{p}$ $>0.05, \mathrm{n}=3$ ) was found when evaluating the data concerning Methods I and II statistically (Figure 2B). According to the study reported by Chelli-Chentouf et al. (32), the TPC of Hoggar Salvadora persica was $70 \mu \mathrm{g}$ GAE/mg dried weight. Similarly, a study by Taha et al. (37) ascertained that TPC of Salvadora persica was calculated as $52.6 \mu \mathrm{g}$ GAE/mg dried weight.

\section{The Trolox equivalent antioxidant capacity of extract}

Oxidative stress stimulated by free radicals might cause many problems in the human body. Antioxidant intake is thus crucial to protect the body from free radicals. Cupric reducing antioxidant capacity (CUPRAC) method was performed to determine the antioxidant levels of aqueous miswak extracts in terms of mg Trolox/L. The study revealed that the antioxidant activity of the aqueous extract was found to be $59.17 \pm 6.23$ and 92.5 $\pm 4.09 \mathrm{mg}$ Trolox/L for Method I and II, respectively (Figure $2 \mathrm{C}$ ). This difference is probably due to the high temperature applied in Method II $(* * \mathrm{p}<0.05, \mathrm{n}=3)$. The antioxidant activities of the miswak species have been determined by applying different methods such as DPPH and ABTS in the literature $(31,33)$. The present study reports the antioxidant activity levels of Salvadora persica extracts in terms of $\mathrm{mg}$ Trolox/L for the first time in the literature. When comparing the results with another study published by our group (21), we concluded that a sufficient antioxidant capacity was achieved in Method II.

\section{Construction of bioengineered scaffolds}

The results related to the isolation and characterization of JC were discussed in depth in the studies previously published by our group $(18,19)$. Structural integrity is one of the main challenges to be overcome when using jellyfish-derived atelocollagen to fabricate novel bioengineered scaffolds which have a proper pore size, mechanical stability, and so on. To address this challenge, MES buffer containing at least $80-90 \%$ ethanol (15) or acetone (38) ( $/ / v)$ is essential for successful cross-linking of such scaffolds. On the other hand, when aqueous miswak extracts were loaded into cross-linked JC scaffolds at ratios of 0.05 and $0.1 \%$, the morphology of miswak extract-laden JC scaffolds slightly shrunk depending on the loaded extract ratio (Figure 2D). It has been a well-known issue that swelling ratio decreases as the degree of cross-linking increases (39). So as to enlighten the effect of the crosslinking process on interconnected pores in the scaffolds, swelling rates (\%) of JC and miswak extract-laden JC scaffolds were investigated. The swelling ratio of JC scaffold was found to be $3291.23 \pm 309.74 \%$, whereas 0.05 and $0.1 \%$ miswak extract-laden JC scaffolds were $2836.75 \pm 341.31 \%$ and $2822.52 \pm 376.16 \%$, respectively. According to results presented by Tronci et al. (40), the highest swelling ratio of collagen type I-based scaffold (derived from rat tail) was found as $1996 \pm 182 \%$. Our findings indicate that JC-based scaffolds have shown remarkable swelling properties when comparing to mammalian-derived alternatives. Lastly, the changes in the morphology and swelling ratio might have arisen from the sticky organic compounds 
(such as terpenes) in the miswak extract $(34,41)$.

\section{In vitro study}

Periodontal layers of healthy premolars were scraped and digested with collagenase type I to isolate the primary hPDLF cells (Figure 3A $C)$. The isolated cells were then expanded at standard culture conditions. While hPDLF cells in the culture environment showed spindle or stellate-shaped morphology at early passages, the appearances of the most cells changed to a spindle-shaped fibroblastic morphology $(42,43)$ and organized in a swirl pattern $(44)$. The microscopic images of isolated hPDLF cells are seen in Figure 3D. The cells were seeded
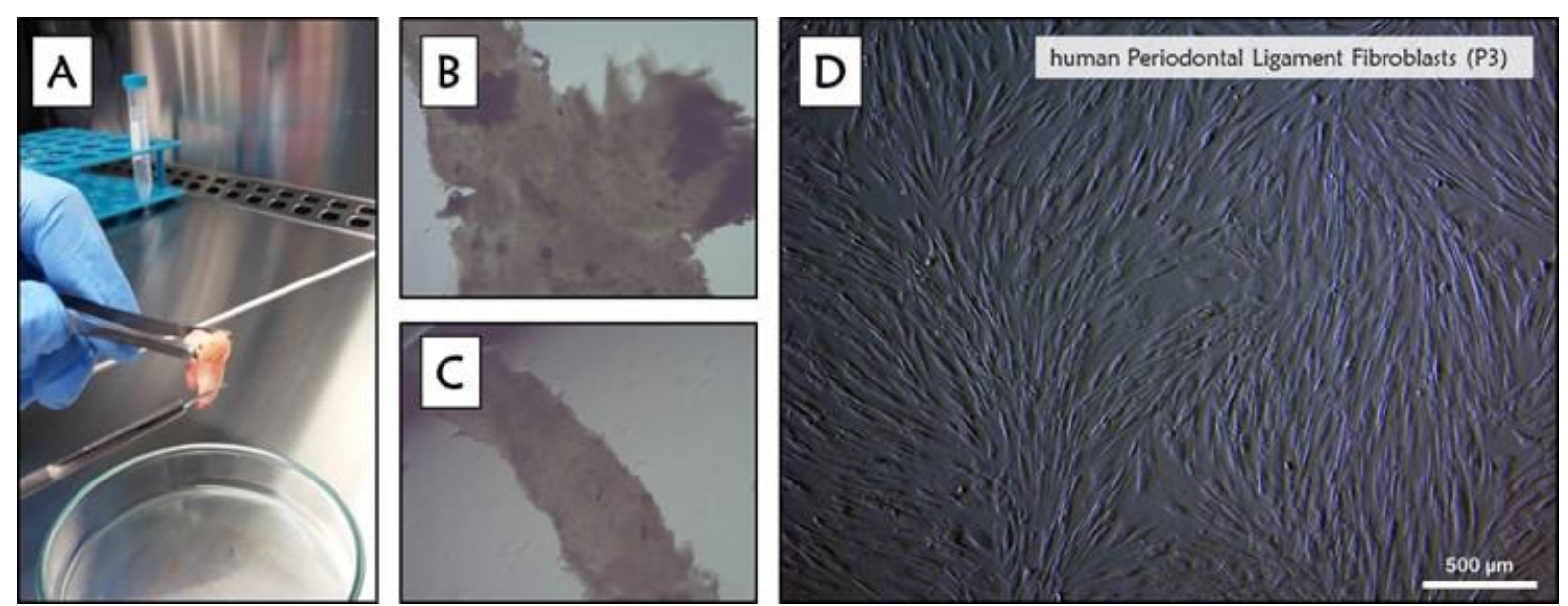

Figure 3. Healthy premolar $(A)$, scraped periodontal layers $(B, C)$ and human periodontal ligament fibroblast cells at Passage 3 (D). Scale bar: $500 \mu \mathrm{m}$.

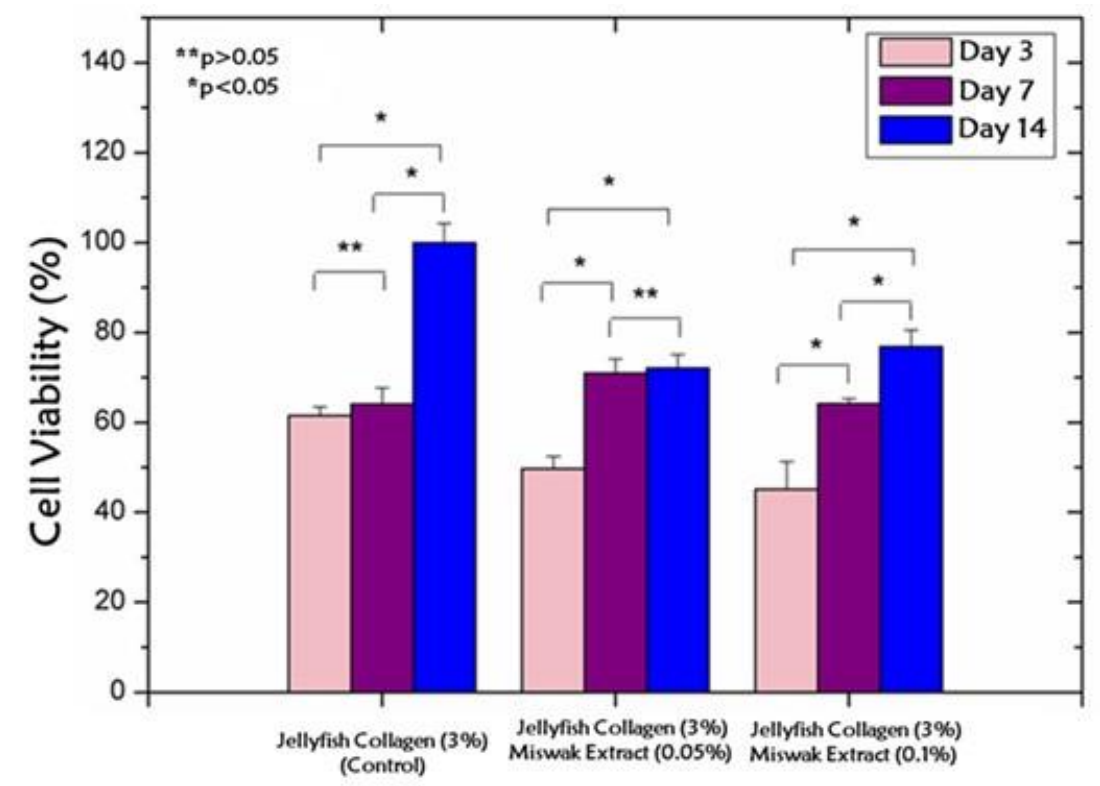

Figure 4. Cell viability assay (MTT-based) for jellyfish collagen (3\%), $0.05 \%$ and $0.1 \%$ miswak extract-laden jellyfish collagen (3\%) scaffolds on days 3, 7 and 14 .

Morphology of scaffolds and cell adhesion

The pore size distributions, 3D interconnections between pores, surface roughness, and so on are the fundamental parameters to be considered in the construction of useful scaffolds for tissue engineering and regenerative medicine. The onto JC and miswak extract-laden JC scaffolds, and the cell viability was determined by MTT assay on the $3^{\text {rd }}, 7^{\text {th }}$ and $14^{\text {th }}$ days. Figure 4 reveals the fabricated scaffolds to have no cytotoxic effects on hPDLF cells. Although cell attachment was observed both $\mathrm{JC}$ and miswak extract-laden JC scaffolds, it was seen that the cell viability on miswak extract-laden JC scaffolds, unexpectedly, remained slightly low compared to JC scaffold ( $* \mathrm{p}<0.05, \mathrm{n}=3$ ). Furthermore, there was no remarkable change in cell viability on 0.05 and $0.1 \%$ miswak extract-laden JC scaffolds ( $* * p>0.05, \mathrm{n}=3$ ) depending on time points. We believe that the pore size of the miswak extract-laden JC scaffolds has affected cell proliferation (45). 
pore size of miswak extract-laden JC scaffolds slightly shrunk depending on the increase in miswak ratio loaded into scaffolds. On the other hand, SEM micrographs revealed hPDLF cells to spread and cover the surfaces of prepared scaffolds on days 3, 7 and 14 to the extent allowed by pore size. These findings are also in close agreement with the MTT results.
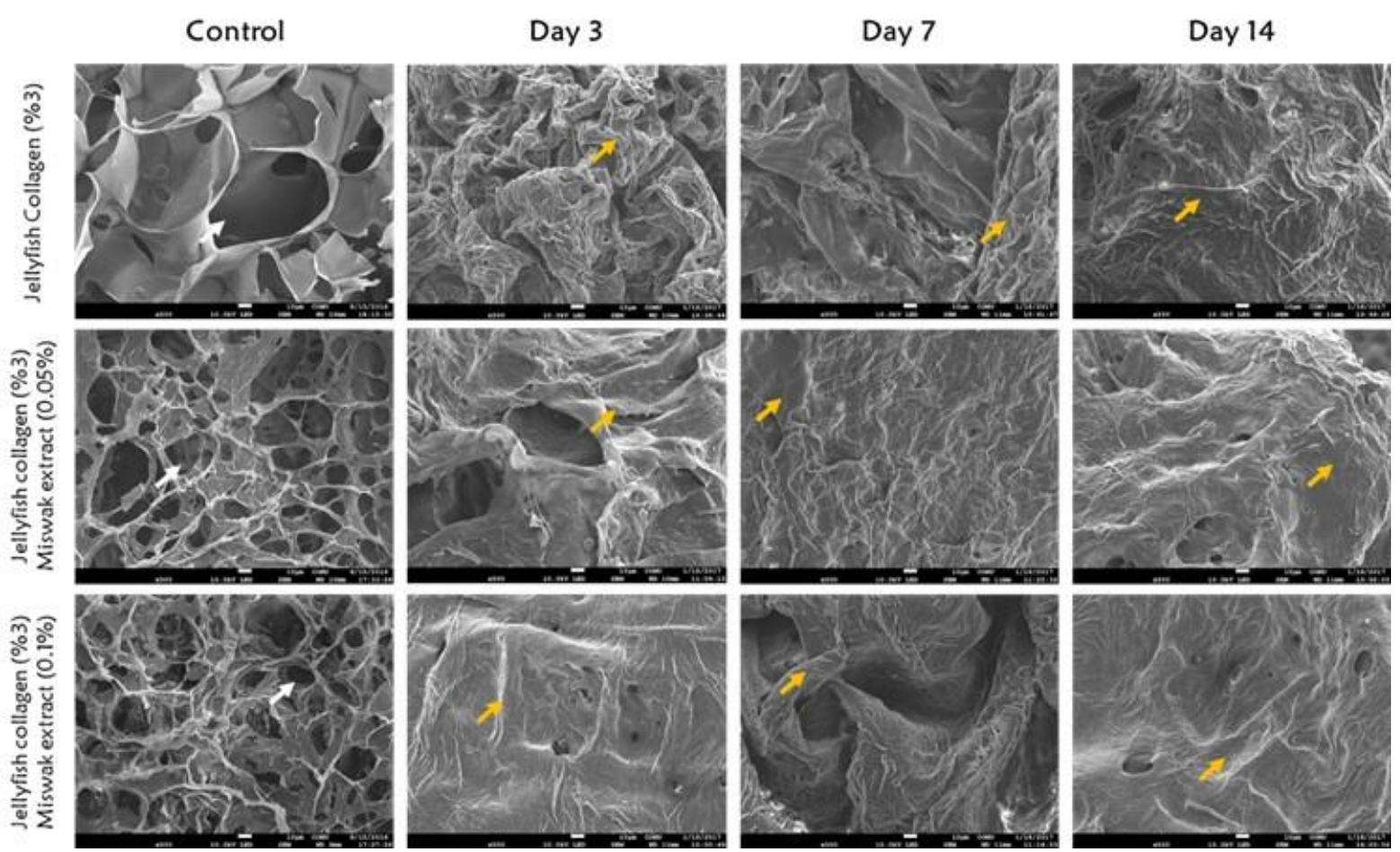

Figure 5. Scanning electron microscopy micrographs (500x) demonstrate the microarchitecture (white arrows) of the prepared scaffolds and hPDLF cell proliferation (yellow arrows) on these surfaces on days 3, 7 and 14 . Scale bars: $10 \mu \mathrm{m}$.

\section{CONCLUSION}

Understanding the role of bioactive molecules derived from medicinal plants in cellular behaviors is substantial with regard to transferring this knowledge to translational medicine concept. Among many medicinal plants, Salvadora persica has the remarkable potential in maintaining and regulating the oral health due to the presence of some unique constituents. To that aim, we fabricated hybrid bioengineered scaffolds using jellyfish collagen and miswak extract. We then sought to evaluate the cellular behaviors of hPDLF such as attachment, growth, and proliferation in both JC and miswak extract-laden JC scaffolds. Miswak extract-laden JC scaffolds supported to cell attachment, but could not affect sufficient cell proliferation and growth compared to JC scaffolds. These results demonstrate that miswak extract has a significant influence on the pore size distribution of JC-based scaffolds. On the other hand, the antimicrobial effects of miswak extracts have been intensely studied in the literature, but there are no studies regarding the use of miswak extracts in periodontal tissue engineering applications. As a result, we believe that miswak extract-laden JC scaffolds could be a notable candidate for periodontal tissue regeneration in the future.

\section{ACKNOWLEDGMENTS}

The research reported here was financially supported by Çanakkale Onsekiz Mart University, Scientific Research Projects Coordination Unit (Project ID. FYL-2016-632). The authors wish to thank Çanakkale Onsekiz Mart University, Science and Technology Application \& Research Center for analyses.

\section{REFERENCES}

1. Inanç $B$, Arslan $Y E$, Seker $S$, Elçin $A E$, Elçin YM. Periodontal ligament cellular structures engineered with electrospun poly(DL-lactideco -glycolide) nanofibrous membrane scaffolds. J Biomed Mater Res Part A. 2009 Jun;90A(1):186-95. Available from: http://doi.wiley.com/10.1002/jbm.a.32066

2. Sokos D, Everts V, de Vries TJ. Role of periodontal ligament fibroblasts in osteoclastogenesis: a review. J Periodontal Res. 2015 Apr;50(2):152-9. Available from: http://doi.wiley.com/10.1111/jre.12197

3. Kim JH, Park $\mathrm{CH}$, Perez RA, Lee HY, Jang JH, Lee $\mathrm{HH}$, et al. Advanced Biomatrix Designs for Regenerative Therapy of Periodontal Tissues. J Dent Res. 2014 Dec 19;93(12):1203-11. Available

from: 
http://journals.sagepub.com/doi/10.1177/00 22034514540682

4. Özdoğan AI, İlarslan YD, Kösemehmetoğlu K, Akca G, Kutlu HB, Comerdov E, et al. In vivo evaluation of chitosan based local delivery systems for atorvastatin in treatment of periodontitis. Int J Pharm. 2018 Oct;550:470$6 . \quad$ Available from: https://linkinghub.elsevier.com/retrieve/pii/S 0378517318306446

5. Hajishengallis G. Immunomicrobial pathogenesis of periodontitis: keystones, pathobionts, and host response. Trends Immunol. 2014 Jan;35(1):3-11. Available from:

http://dx.doi.org/10.1016/j.it.2013.09.001

6. Han J, Menicanin D, Gronthos S, Bartold P. Stem cells, tissue engineering and periodontal regeneration. Aust Dent J. 2014 Jun;59(SUPPL. 1):117-30. Available from: http://doi.wiley.com/10.1111/adj.12100

7. Chahal S, Hussain FSJ, Kumar A, Rasad MSBA, Yusoff MM. Fabrication, characterization and in vitro biocompatibility of electrospun hydroxyethyl cellulose/poly (vinyl) alcohol nanofibrous composite biomaterial for bone tissue engineering. Chem Eng Sci. 2016 Apr;144:17-29. Available from: http://dx.doi.org/10.1016/j.ces.2015.12.030

8. Chen F-M, Zhao Y-M, Jin Y, Shi S. Prospects for translational regenerative medicine. Biotechnol Adv. 2012 May;30(3):658-72. Available from: http://dx.doi.org/10.1016/j.biotechadv.2011. 11.005

9. Inanc $B$, Elcin $A E$, Elcin $Y M$. Osteogenic Induction of Human Periodontal Ligament Fibroblasts Under Two- and ThreeDimensional Culture Conditions. Tissue Eng. 2006 Feb;12(2):257-66. Available from: https://www.liebertpub.com/doi/10.1089/ten .2006.12.257

10. Qasim SB, Delaine-Smith RM, Fey $\mathrm{T}$, Rawlinson A, Rehman IU. Freeze gelated porous membranes for periodontal tissue regeneration. Acta Biomater. 2015 Sep;23:317-28. Available from: http://dx.doi.org/10.1016/j.actbio.2015.05.0 01

11. Wu C, Zhou Y, Lin C, Chang J, Xiao Y. Strontium-containing mesoporous bioactive glass scaffolds with improved osteogenic/cementogenic differentiation of periodontal ligament cells for periodontal tissue engineering. Acta Biomater. 2012 Oct;8(10):3805-15. Available from: http://dx.doi.org/10.1016/j.actbio.2012.06.0 23
12. Hatayama $T$, Nakada A, Nakamura $H$, Mariko W, Tsujimoto G, Nakamura $T$. Regeneration of gingival tissue using in situ tissue engineering with collagen scaffold. Oral Surg Oral Med Oral Pathol Oral Radiol. 2017 Oct;124(4):348-54. Available from: https://doi.org/10.1016/j.000o.2017.05.471

13. Kuttappan S, Mathew D, Nair MB. Biomimetic composite scaffolds containing bioceramics and collagen/gelatin for bone tissue engineering - A mini review. Int J Biol Macromol. 2016 Dec;93:1390-401. Available from:

http://dx.doi.org/10.1016/j.ijbiomac.2016.06 .043

14. Montalbano G, Toumpaniari S, Popov A, Duan P, Chen J, Dalgarno K, et al. Synthesis of bioinspired collagen/alginate/fibrin based hydrogels for soft tissue engineering. Mater Sci Eng C. 2018 Oct;91:236-46. Available from:

https://doi.org/10.1016/j.msec.2018.04.101

15. Hoyer B, Bernhardt A, Lode A, Heinemann $S$, Sewing J, Klinger $M$, et al. Jellyfish collagen scaffolds for cartilage tissue engineering. Acta Biomater. 2014 Feb;10(2):883-92. Available from:

https://linkinghub.elsevier.com/retrieve/pii/S 1742706113005394

16. Jongjareonrak A, Benjakul $S$, Visessanguan W, Nagai T, Tanaka M. Isolation and characterisation of acid and pepsinsolubilised collagens from the skin of Brownstripe red snapper (Lutjanus vitta). Food Chem. 2005 Dec;93(3):475-84. Available from: http://linkinghub.elsevier.com/retrieve/pii/SO 308814604007666

17. Pustlauk W, Paul B, Gelinsky M, Bernhardt A. Jellyfish collagen and alginate: Combined marine materials for superior chondrogenesis of hMSC. Mater Sci Eng C. 2016 Jul;64:190-8. Available from: http://dx.doi.org/10.1016/j.msec.2016.03.08 1

18. Arslan YE, Sezgin Arslan T, Derkus B, Emregul E, Emregul KC. Fabrication of human hair keratin/jellyfish collagen/eggshell-derived hydroxyapatite osteoinductive biocomposite scaffolds for bone tissue engineering: From waste to regenerative medicine products. Colloids Surfaces B Biointerfaces. 2017 Jun;154:160-70. Available from: http://linkinghub.elsevier.com/retrieve/pii/SO 927776517301522

19. Derkus B, Arslan YE, Bayrac AT, Kantarcioglu I, Emregul KC, Emregul E. Development of a novel aptasensor using 
jellyfish collagen as matrix and thrombin detection in blood samples obtained from patients with various neurodisease. Sensors Actuators B Chem. 2016 Jun;228:725-36. Available from: https://linkinghub.elsevier.com/retrieve/pii/S 0925400516300958

20. Putra $A B N$, Nishi K, Shiraishi R, Doi $M$, Sugahara $T$. Jellyfish collagen stimulates maturation of mouse bone marrow-derived dendritic cells. J Funct Foods. 2015 Apr;14:308-17. Available from: http://dx.doi.org/10.1016/j.jff.2015.02.008

21. Efe B, Galata YF, Arslan YE. Assessment of the Cytotoxicity of Melia azedarach L. Extracts on Human Adipose-derived Mesenchymal Stem Cells. Hacettepe J Biol Chem. 2018;46(1):121-8.

22. Khan $H$. Medicinal Plants in Light of History. J Evid Based Complementary Altern Med. 2014 Jul;19(3):216-9. Available from: http://journals.sagepub.com/doi/

$10.1177 / 2156587214533346$

23. Petrovska B. Historical review of medicinal plants' usage. Pharmacogn Rev. 2012;6(11):1-5. Available from: http://www.phcogrev.com/text.asp?2012/6/1 $1 / 1 / 95849$

24. Farag MA, Fahmy S, Choucry MA, Wahdan MO, Elsebai MF. Metabolites profiling reveals for antimicrobial compositional differences and action mechanism in the toothbrushing stick "miswak" Salvadora persica. J Pharm Biomed Anal. 2017 Jan;133:32-40. Available from: http://dx.doi.org/10.1016/j.jpba.2016.11.01 8

25. Halawany HS. A review on miswak (Salvadora persica) and its effect on various aspects of oral health. Saudi Dent J. 2012 Apr;24(2):63-9. Available from: http://dx.doi.org/10.1016/j.sdentj.2011.12.0 04

26. Abhary M, Al-Hazmi A-A. Antibacterial activity of Miswak (Salvadora persica L.) extracts on oral hygiene. J Taibah Univ Sci. 2016 Oct 16;10(4):513-20. Available from: http://linkinghub.elsevier.com/retrieve/pii/S1 658365515001661

27. Singleton VL, Rossi JA. Colorimetry of Total Phenolics with Acid Reagents. Am J Enol Vitic. $1965 ; 16(3): 144-58$.

28. Apak R, Güçlü K, Özyürek M, Çelik SE. Mechanism of antioxidant capacity assays and the CUPRAC (cupric ion reducing antioxidant capacity) assay. Microchim Acta. 2008 Apr 21;160(4):413-9. Available from: http://link.springer.com/10.1007/s00604007-0777-0

29. Buttafoco L, Kolkman NG, EngbersBuijtenhuijs P, Poot AA, Dijkstra PJ, Vermes I, et al. Electrospinning of collagen and elastin for tissue engineering applications. Biomaterials. 2006 Feb;27(5):724-34. Available from: http://linkinghub.elsevier.com/retrieve/pii/SO 142961205005910

30. Kaczmarek B, Sionkowska A, Stojkovska J. Scaffolds based on chitosan and collagen with glycosaminoglycans cross- linked by tannic acid. Polym Test. 2018 Jul;65:163-8. Available from: https://doi.org/10.1016/j.polymertesting.201 7.11.026

31. Mohamed SA, Khan JA. Antioxidant capacity of chewing stick miswak Salvadora persica. BMC Complement Altern Med. 2013 Dec 21;13(40):1-6. Available from: BMC Complementary and Alternative Medicine

32. Chelli-Chentouf N, Tir Touil Meddah A, Mullié $C$, Aoues A, Meddah B. In vitro and in vivo antimicrobial activity of Algerian Hoggar Salvadora persica L. extracts against microbial strains from children's oral cavity. J Ethnopharmacol. 2012 Oct;144(1):57-66. Available from: http://linkinghub.elsevier.com/retrieve/pii/SO 378874112005508

33. Noumi E, Snoussi M, Trabelsi N, Hajlaoui $\mathrm{H}$, Ksouri R, Valentin $\mathrm{E}$, et al. Antibacterial, anticandidal and antioxidant activities of Salvadora persica and Juglans regia $\mathrm{L}$. extracts. J Med Plants Res. 2011 Jul $1 ; 5(17): 4138-46$.

34. Naeini A, Jalayer Naderi N, Shokri $H$. Analysis and in vitro anti- Candida antifungal activity of Cuminum cyminum and Salvadora persica herbs extracts against pathogenic Candida strains. J Mycol Med. 2014 Mar;24(1):13-8. Available from: http://dx.doi.org/10.1016/j.mycmed.2013.09 .006

35. Sofrata A, Santangelo EM, Azeem M, BorgKarlson A-K, Gustafsson A, Pütsep K. Benzyl Isothiocyanate, a Major Component from the Roots of Salvadora Persica Is Highly Active against Gram-Negative Bacteria. Heimesaat MM, editor. PLoS One. 2011 Aug $1 ; 6(8)$ :e23045. Available from: https://dx.plos.org/10.1371/journal.pone.00 23045

36. Daferera DJ, Ziogas BN, Polissiou MG. GCMS Analysis of Essential Oils from Some Greek Aromatic Plants and Their Fungitoxicity on Penicillium digitatum. J Agric Food Chem. 
2000 Jun;48(6):2576-81. Available from: http://pubs.acs.org/doi/abs/10.1021/jf99083 $5 x$

37. Taha E, Mariod A, Abouelhawa S, ElGeddawy $M$, Sorour $M$, Matthäus B. Antioxidant activity of extracts from six different Sudanese plant materials. Eur J Lipid Sci Technol. 2010 Nov;112(11):1263-9. Available from: http://doi.wiley.com/10.1002/ejlt.201000326

38. Song $\mathrm{E}$, Yeon Kim S, Chun $\mathrm{T}$, Byun $\mathrm{H}-\mathrm{J}$, Lee YM. Collagen scaffolds derived from a marine source and their biocompatibility. Biomaterials. 2006 May;27(15):2951-61. Available from: http://linkinghub.elsevier.com/retrieve/pii/SO 142961206000147

39. Rehakova M, Bakos D, Vizarova K, Soldan $M$, Jurickova $M$. Properties of collagen and hyaluronic acid composite materials and their modification by chemical crosslinking. J Biomed Mater Res. 1996 Mar;30(3):369-72. Available from: http://doi.wiley.com/10.1002/\%28SICI\%291 097-

$4636 \% 28199603 \% 2930 \% 3$ АЗ\%3С369\%3А\% 3AAID-JBM11\%3E3.0.CO\%3B2-F

40. Tronci G, Grant CA, Thomson NH, Russell SJ, Wood DJ. Multi-scale mechanical characterization of highly swollen photoactivated collagen hydrogels. J R Soc Interface. 2014 Nov 19;12(102):20141079. Available from: http://rsif.royalsocietypublishing.org/cgi/doi/ 10.1098/rsif.2014.1079

41. Tabatabaei F, Moezizadeh M, Javand F.
Effects of extracts of Salvadora persica on proliferation and viability of human dental pulp stem cells. J Conserv Dent. 2015;18(4):31520. Available from: http://www.jcd.org.in/text.asp?2015/18/4/31 $5 / 159740$

42. Şeker Ş, Elçin $A E$, Yumak $T$, Sınağ $A$, Elçin YM. In vitro cytotoxicity of hydrothermally synthesized ZnO nanoparticles on human periodontal ligament fibroblast and mouse dermal fibroblast cells. Toxicol Vitr. 2014 Dec;28(8):1349-58. Available from: https://linkinghub.elsevier.com/retrieve/pii/S 0887233314001313

43. Zhan D, Guo L, Zheng L. Inhibition of the receptor for advanced glycation promotes proliferation and repair of human periodontal ligament fibroblasts in response to high glucose via the NF-KB signaling pathway. Arch Oral Biol. 2018 Mar;87:86-93. Available from: https://doi.org/10.1016/j.archoralbio.2017.1 2.011

44. Duan X, Ji M, Deng F, Sun Z, Lin Z. Effects of connective tissue growth factor on human periodontal ligament fibroblasts. Arch Oral Biol. 2017 Dec;84(51):37-44. Available from: https://linkinghub.elsevier.com/retrieve/pii/S 0003996917302819

45. O'Brien FJ, Harley BA, Yannas IV, Gibson LJ. The effect of pore size on cell adhesion in collagen-GAG scaffolds. Biomaterials. 2005 Feb;26(4):433-41. Available from: http://linkinghub.elsevier.com/retrieve/pii/SO 142961204002017. 
Arslan YE, Kantarcioglu I. JOTCSA. 2019; 6(1): 51-62.

RESEARCH ARTICLE 